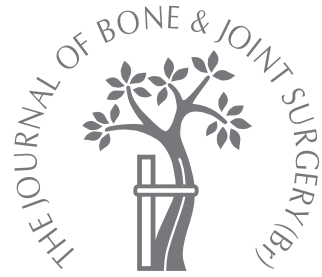

C. Lee,

S. Lashari

From Newham

University Hospital,

London, England
- C. Lee, BSc(Hons), MBBS, Senior House Officer

I. Lashari, FRCS, MSc(Orth), FRCS(Orth), Consultant Orthopaedic Surgeon Department of Orthopaedics Newham University Hospital, Glen Road, Plaistow, London E13 8SL, UK.

Correspondence should be sent to Mr S. Lashari; e-mail: Shahbux.lashari@newhamheal th.nhs.uk

(C)2007 British Editorial Society of Bone and Joint Surgery doi:10.1302/0301-620X.89B7. $18425 \$ 2.00$

$J$ Bone Joint Surg [Br] 2007;89-B:956-8.

Received 17 July 2006;

Accepted after revision 6 February 2007

- CASE REPORT

\title{
Pseudofracture of the neck of femur secondary to osteomalacia
}

\begin{abstract}
Nutritional osteomalacia is a metabolic bone disorder common among the Asian female immigrant population in the United Kingdom. We describe the case of a female of Asian origin, who was found to have a unilateral undisplaced pseudofracture of the neck of the femur during pregnancy. Although not operated on the fracture was treated successfully with calcium and vitamin D supplement therapy. Within one month of treatment, the bone pain subsided and she was able to bear full weight. Subsequent radiological follow-up showed the pseudofracture to have healed sufficiently with no evidence of avascular necrosis.
\end{abstract}

There should be a high index of suspicion of this disease, particularly among Asian patients presenting with persistent and non-specific musculoskeletal pain.

A pseudofracture of the neck of the femur is an uncommon complication of osteomalacia, and may be difficult to treat. We describe the case of a female of Asian origin who presented with such a fracture during pregnancy.

\section{Case report}

A 20-year-old female of Asian origin who was in the third trimester of pregnancy presented with a three-month history of intermittent bilateral hip pain. She had experienced some discomfort in the groin for the past few months on walking and recalled losing her balance and straining her right hip while getting out of bed in the maternity ward. There was no history of direct trauma. Her past medical and obstetric history was unremarkable. She was not on any medication apart from vitamin supplements. She did not drink alcohol or smoke. Since moving to the United Kingdom from India three years earlier, she had stayed indoors most of the time and had very little exposure to the sun. She always wore a black veil when out of doors. She ate meat, but had a low consumption of dairy products.

On examination, she was slim and walked with a waddling gait. Movements of her right hip were mildly painful on abduction and internal rotation. No other obvious abnormality was found. The serum calcium was $1.95 \mathrm{mmol} / \mathrm{L}$ (reference range 2.02 to 2.6), phosphate $0.6 \mathrm{mmol} / \mathrm{L}(0.83$ to 1.49$)$, alkaline phosphatase $932 \mathrm{IU} / \mathrm{L}$ (64 to 306 ) and the 25 hydroxy Vitamin D was $19 \mathrm{mmol} / \mathrm{L}$ (50 to
100). The kidney, liver and thyroid function tests were all normal. The anteroposterior radiograph (Fig. 1) and MRI scan (Fig. 2) of the right hip showed an undisplaced transcervical pseudofracture of the neck of femur. She was treated with therapeutic doses of calcium and vitamin D supplements but had no surgical intervention. She was discharged three days after delivery of a healthy daughter. She was advised to increase her calcium intake by consuming dairy and poultry products, especially eggs and milk, and to expose herself to regular sunlight. She was also advised to take strenuous exercise after a few months and not to breast feed. At follow-up after three weeks symptoms had improved significantly and she was walking without pain. Radiographs of the right hip after three weeks (Fig. 3a), three months (Fig. 3b) and 12 months (Fig. 3c) showed progressive satisfactory healing of the pseudofracture. Her blood tests improved with a serum calcium of 2.05 $\mathrm{mmol} / \mathrm{L}$ (2.02 to 2.6 ), phosphate $1.3 \mathrm{mmol} / \mathrm{L}$ (0.83 to 1.49$)$ and the alkaline phosphatase 422 IU/L (64 to 306) at three weeks after calcium and vitamin D supplement therapy was initiated.

\section{Discussion}

Nutritional osteomalacia is rare in Western society but remains a common metabolic bone disorder in Asian immigrants, ${ }^{1}$ especially in women of reproductive age from a lower 


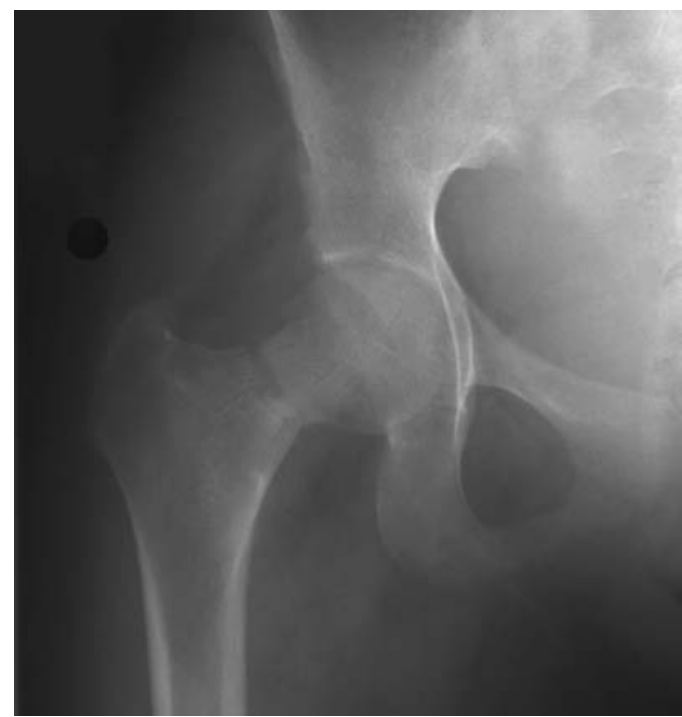

Fig. 1

Anteroposterior radiograph of the right hip showing an undisplaced transcervical pseudofracture of the right femur.

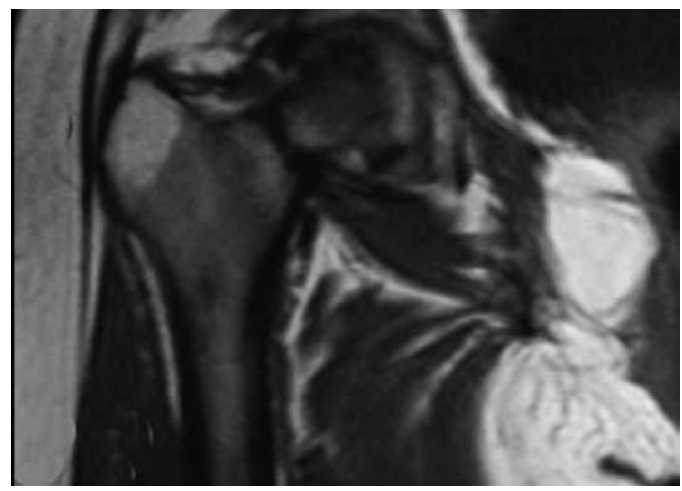

Fig. 2

MRI showing an undisplaced transcervical pseudofracture of the right femur.

socio-economic background. It is often underdiagnosed in the United Kingdom, although it has been highlighted in the literature since the 1960 s. $^{2}$

A recent study reports an average delay of 59 months before diagnosis is made, and another showed a prevalence of $78 \%$ of hypovitaminosis $\mathrm{D}_{3}$ in an Indo-Asian population attending a rheumatology clinic in the United Kingdom, compared with $58 \%$ in controls. ${ }^{3}$ These women usually complain of chronic backache as well as generalised aches and pains, but orthopaedic complications are infrequent.

The combination of dietary deficiency of vitamin D, lack of exposure to sunlight, especially in women who wear traditional dress such as the burka, limited intake of calcium and frequent pregnancies with subsequent lactation, severely affect the calcium metabolism, resulting in a nega-

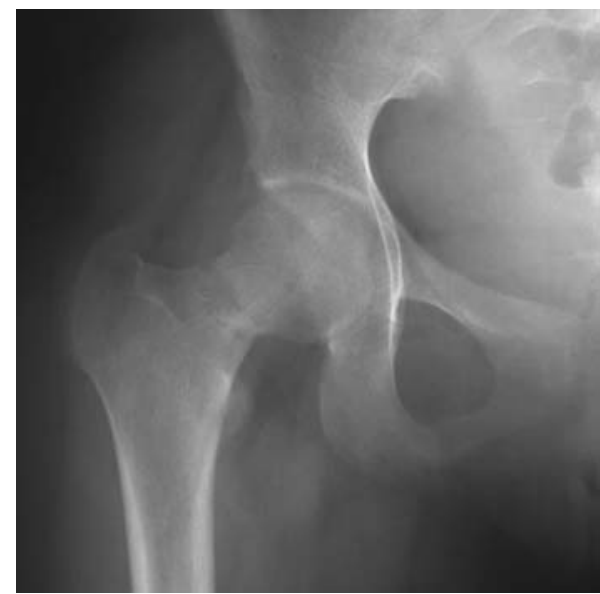

Fig. 3a

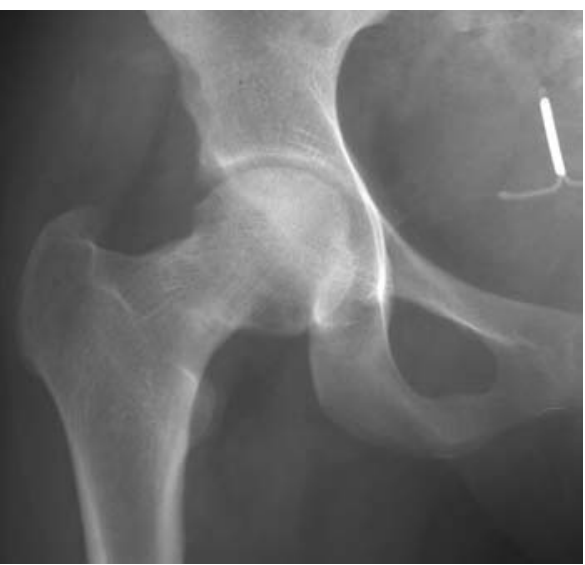

Fig. 3b

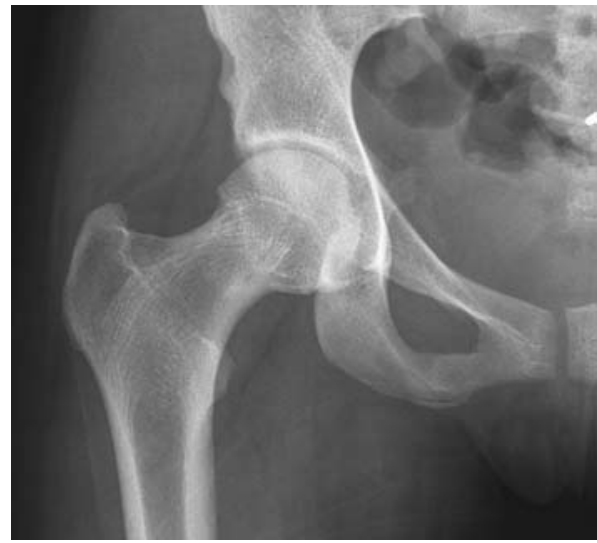

Fig. 3c

Anteroposterior radiograph of the right hip at a) three weeks, b) three months and c) 12 months showing progressive healing of the pseudofracture (Looser's zone) on treatment with vitamin D and calcium replacement.

tive calcium balance. ${ }^{4}$ It is also thought that phytates in the flour used for unleavened chapatti bread may inhibit the normal absorption of calcium from the stomach. ${ }^{5,6}$ Radio- 
logically, osteomalacia presents with generalised osteopenia and multiple, often symmetrical radiolucent lines in the cortex perpendicular to the long axis of the bone. They are referred to as 'Looser's zones' or 'Pseudofractures'. They represent cortical stress fractures filled with poorly mineralised callus and fibrous tissue and are common along the axillary margins of the scapulae, the neck of the femur, the ribs and the pubic ramii. ${ }^{7}$ A pseudofracture may, in rare circumstances, become the site of a true fracture, presumably as a result of torsional, tensile or shearing stress on the weakened area in the bone. Occasionally, the patient may present with an acute fracture leading to the diagnosis of the primary disease. A high index of suspicion of underlying calcium deficiency is essential for the early diagnosis of the condition and to avoid potentially serious complications.

Pseudofractures in the femoral neck often heal with calcium and vitamin D supplements if the diagnosis is made early. ${ }^{8-12}$ Surgical intervention is not usually required unless they progress to displaced fractures. Not all pseudofractures should be fixed prophylactically, despite the potential complications seen in intracapsular fractures of the neck of the femur. This possibility must be considered and patients should be followed up regularly for a minimum of one year. The sudden onset or exacerbation of pain at the site of a pseudofracture, the loss of active movement and an inability to bear weight should all alert the surgeon to the possibility of acute displacement, and requires immediate operation. As illustrated by this case, provided that the pseudofracture in the femoral neck remains undisplaced, healing will progress once medical treatment is started, except perhaps in patients with hypophosphatasia. ${ }^{13,14}$

It is important to monitor the patient closely during treatment. Excessive dosage with vitamin $\mathrm{D}$ and mineral supplements may lead to hypercalcaemia, which is characterised by anorexia, nausea, vomiting, abdominal pain, confusion and even seizures. Should surgery become necessary, patients should be mobilised as soon as possible to allow resumption of medical treatment and prevent delayed mineralisation of the callus. ${ }^{15}$

No benefits in any form have been received or will be received from a commercial party related directly or indirectly to the subject of this article.

\section{References}

1. Hodgkin P, Hine PM, Kay GH, Lumb GA, Stanbury SW. Vitamin-D deficiency in Asians at home and in Britain. Lancet 1973;2:167-71.

2. Ford JA, Colhoun EM, McIntosh WB, Dunnigan MG. Rickets and osteomalacia in the Glasgow Pakistani community, 1961-71. Br Med J 1972;2:677-80.

3. de Torrente de la Jara G, Pecoud A, Favrat B. Musculoskeletal pain in female asylum seekers and hypovitaminosis $\mathbf{D}_{3}$. BMJ 2004;329:156-7.

4. Henry A, Bowyer L. Fracture of the neck of femur and osteomalacia in pregnancy. BJOG 2003;110:329-30.

5. Fredlund K, Isaksson M, Rossander-Hulthen L, Almgren A, Sandberg AS. Absorption of zinc and retention of calcium: dose dependent inhibition by phytate. J Trace Elem Med Bio/ 2006;20:49-57.

6. Sasson A, Etzion Z, Shany S, Berlyne GM, Yagil R. Growth and bone mineralization as affected by dietary calcium, phytic acid and vitamin D. Comp Biochem Physiol A 1982;72:43-8.

7. Greenspan A. Orthopaedic radiology: a practical approach. Philadelphia: Gower Medical Publishing. J B Lippincott Co, 1988:20-8.

8. Faraj A. Bilateral simultaneous combined intra- and extracapsular femoral neck fracture secondary to nutritional osteomalacia: a case report. Acta Orthop Belg 2003;69:201-3

9. Oliveri B, Gomer Acotto C, Mautalen C. Osteomalacia in a patient with severe anorexia nervosa. Rev Rhum Engl Ed 1999;66:505-8.

10. Berger CE, Marteau R, Pabinger C, et al. Decreased cutaneous vitamin D-synthesis in heavily melanized individuals: a rare cause for pathologic fractures of the hip. Wien Klin Wochenschr 2003;115:186-90.

11. El-Desouki MI, Othman SM, Fouda MA. Bone mineral density and bone scintigraphy in adult Saudi female patients with osteomalacia. Saudi Medical Journal 2004;25:355-8.

12. Goraya JS, Gupta PN, Gupta RK, Bahadur R, Parmar VR. Anticonvulsant induced osteomalacia. Indian Pediatrics 2000;37:296-307.

13. Mankin HJ. Rickets, osteomalacia and renal osteodystrophy. J Bone Joint Surg [Am] 1974;56-A:101-28.

14. Laroche M. Phosphate, the renal tubule, and the musculoskeletal system. J Bone Spine 2001;68:211-15.

15. Canale ST. Campbell's operative orthopaedics. Ninth ed. Mosby-Year Book, 1998:887-90. 